\title{
Shoot Growth Rate and Density Affect Bud Necrosis of 'Riesling' Grapevines
}

\author{
Tony K. Wolf and M. Kay Warren \\ Winchester Agricultural Research and Extension Center, Virginia Tech, 595 Laurel Grove Road, \\ Winchester, VA 22602 \\ Additional index words. bud abortion, paclobutrazol, shade, Vitis vinifera
}

\begin{abstract}
Examination of 'R iesling' grape (Vitis vinifera L.) in Virginia suggested that a high incidence of bud necrosis (BN) in some vineyards was associated with canopy shade and rapid shoot growth. B N appeared to originate as an abortion and dehydration of the primary, and occasionally secondary, buds of the developing dormant bud. BN frequency was lowest among the basal four nodes of a given shoot or cane, and increased in frequency through node 20. Experiments were conducted in 1991 and 1992 to evaluate the specific involvement of shoot growth rate and canopy shade on 'R iesling' BN. Shoot growth rate (SGR), measured in a 17-day period around bloom, had a significant, positive relationship with BN in one of two vineyards. BN was positively associated with cane diameter and average internode length. Applying the growth retardant paclobutrazol significantly reduced SGR and BN incidence up to $80 \%$ among nodes 6 to 15 in two separate vineyards. Artificial shade (64\% or $92 \%$ reduction in photosynthetic photon flux), suspended over vine canopies in the 3-week period before véraison, did not affect BN. Shoots of canopies that had been thinned before bloom to $10 \mathrm{shoots} / \mathrm{m}$ of canopy expressed slightly lower BN levels than shoots sampled from canopies that had been thinned to 20 shoots per meter. 'R iesling' BN appeared more influenced by shoot vigor than shade under Virginia growing conditions. Chemical

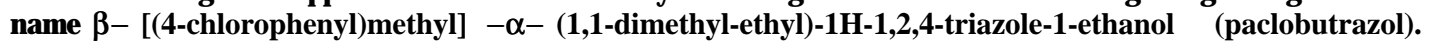

Tissue- and organ-specific necroses occur among many horticultural crops and include a bud necrosis of black currant (Ribes nigrum L.) (Gill, 1985), noninfectious bud failure of almond (Prunus amygdulus Batsch) (Hellali et al., 1978), bract necrosis of poinsettia (Euphorbia pulcherrima Willd.) (Simons and Smith, 1991), and bunch stem necrosis of grape (Vitis vinifera) (Christensen and Boggero, 1985). Grape BN reduces budbreak, fruitfulness, and crop yields (Dry and Coombe, 1994; Lavee et al., 1981; Perez and Kliewer, 1990). The failure to associate pathogens or pests with grape BN suggests that the disorder may result from impaired physiological or developmental processes. BN has been described in seedless grape cultivars, including 'Thompson Seedless', 'Flame Seedless' and 'Queen of Vineyard' (Lavee, 1987; Lavee et al., 1981; Morrison and Iodi, 1990; Naito et al., 1987; Perez and Kliewer, 1990; Perez-Harvey, 1991), and in seeded cultivars (Dry and Coombe, 1994; Naito et al., 1985; Naito et al., 1986). Reduced fruitfulness associated with blind nodes (Pastena, 1990) and reduced budbreak observed in shading experiments (May et al., 1976) might also be due to $\mathrm{BN}$ in some cases.

Grape bud development occurs over 2 years, with initiation and much of the development occurring in the first year and emergence as a shoot occurring in the second year (Pratt, 1974). BN symptoms become evident in the first year of development, around bloom time of the current season's flower clusters; additional buds may be affected until the onset of bud dormancy (Lavee et al., 198 1; Morrison and Iodi, 1990; Perez and Kliewer, 1990). The necrosis usually originates at the base of the primary bud, leading only to death of this bud. Under this condition, one or more of the secondary buds, of inferior fruitfulness, may emerge the following spring. Under more acute conditions, necrosis may involve secondary buds (usually two) leading to absence

Received for publication 9 Feb. 1995. Accepted for publication 3 July 1995. Financial support was provided by the Virginia Winegrowers Advisory Board. The cost of publishing this paper was defrayed in part by the payment of page charges. Under postal regulations, this paper therefore must be hereby marked advertisement solely to indicate this fact. of shoot growth from that node (Lavee et al., 1981; Perez and Kliewer, 1990). Histological examinations showed that 'Thompson Seedless' BN was preceded by the formation of a transverse band of compressed and irregularly shaped cells at one or more nodes of the primary bud axis (Morrison and Iodi, 1990). Cell lysis in that zone was followed by death and drying of the distal tissues.

The cause of grape BN remains unclear. High shoot vigor (Bindra and Chohan, 1975; Dry and Coombe, 1994; Lavee et al.. 1981; Naito et al., 1986) and either whole-shoot or individual bud shading (Perez and Kliewer, 1990) increased BN frequency in BNprone vineyards. Applying the chemical growth retardant succinic acid-2, 2-dimethylhydrazine reduced BN incidence (Naito et al., 1986), whereas applying gibberellic acid increased BN (Ziv et al.. 1981; Naito et al., 1986); but gibberellic acid had no effect in a vineyard not prone to BN (Morrison and Iodi, 1990).

Surveys and experiments were conducted to investigate potential causes of a BN disorder of 'Riesling' winegrapes in Virginia. Experimental objectives were to evaluate the influence of shoot exposure and shoot growth rate (SGR) on BN incidence.

\section{Materials and Methods}

Vineyard surveys. Surveys were conducted in July and November 1990 to explore possible associations between BN incidence and shoot, vine, and vineyard features. The July survey corresponded to about 6 weeks after bloom. The November survey was done after natural defoliation. Six 'Riesling' vineyards located throughout the Piedmont region and northern Virginia were surveyed at each period, with 25 to 30 randomly collected shoots examined in each vineyard. Vines in all vineyards were 7 to 12 years old. Survey parameters included vineyard topography, relative shoot diameter and internode length, node position of the bud, and whether the node bore a strong summer lateral (Pratt, 1974). that is, a lateral that was likely to persist after fall frost. In four vineyards, a cursory examination (5 to 10 shoots) was also made of 'Chardonnay' vines planted adjacent to the 'Riesling' blocks. Except for two vineyards, vines were cordon-trained, pruned to two- or three-node spurs, with shoots positioned to grow vertically 
upright. At Prince Michel Vineyard, vines were head-trained and cane-pruned, using canes 10 to 12 nodes long. At Meredyth Vineyard, vines were trained to high, bilateral cordons and spurpruned to two- to four-node spurs. Shoots were positioned to grow downward and were not hedged. Survey data were obtained by recording descriptive information on the shoot or cane, the vine, and the vineyard. The shoot or cane was then removed from the vine, and buds at nodes 1-20 were sectioned with a razor and visually examined for BN. Primary buds were considered necrotic if they appeared light tan to dark brown. Necrotic buds were often dry and crumbly. Secondary buds were often dead, but no effort was made to quantify BN incidence in these buds.

$\mathrm{BN}$ surveys were repeated in some vineyards (Prince Michel and Somerset) every fall. For comparison with the 1990 season, data collected from three 'Riesling' vineyards in December 1993 are included. Again, 25 to 30 visibly well matured canes of moderate diameter (6.0 to $8.5 \mathrm{~mm})$, taken from canopy positions that were likely well exposed to sunlight during the growing season were examined at each vineyard. BN incidence was determined among the first 20 nodes of each cane.

Shoot exposure. The relationship between shoot exposure and $\mathrm{BN}$ incidence was examined in three 'Riesling' vineyards in August and early September 1991. Photosynthetic photon flux (PPF) in the canopy, shoot diameter, and average internode length were quantified. Shoots were first visually scored based on their relative sky exposure (exposed, partly shaded, or shaded). PPF values were then measured at shoot nodes 5 and 10 and above the vine canopy to obtain a maximum available PPF reading. For readings taken at shoot nodes within the canopy, the sensor was generally aimed directly toward the canopy exterior to obtain maximal PPF readings. PPF measures were used to estimate the average percentage available PPF received at nodes 5 and 10 at the time of measure. PPF values were obtained with a $1.0-\mathrm{cm}$ quantum sensor (model LI-190SB; LI-COR, Lincoln, Neb.) and a photometer (model LI-185B). The shoots were then removed from the vine and the maximum diameter of the stem between nodes two and three (from shoot base) and the total length of the first 20 nodes and internodes were recorded. Buds of the first 20 nodes were then sectioned and assessed for BN. Twenty-five to 30 shoots within each exposure category were examined in this manner between 1100 and 1400 HR on 2 days.

Leaf petiole samples consisting of three replicate samples of 100 petioles were collected at bloom in 1991. Petiole samples were collected from five 'Riesling' vineyards and were processed by a commercial laboratory for essential element concentrations.

SGR. Relationships between early-season SGR and cumulative $\mathrm{BN}$ incidence were studied in two 'Riesling' vineyards during the 1991 growing season. At Prince Michel Vineyard, vines were spaced $1.1 \mathrm{~m}$ apart in rows $2.7 \mathrm{~m}$ wide and were trained to a pendelbogen system, which consisted of a low head $(1.0 \mathrm{~m}$ above ground), cane pruning, and upright shoot growth maintained with the aid of foliage catch wires. Shoot density was standardized at about 10 shoots per meter of canopy. Three shoots, on each of five vines, in 10 randomly selected plots (replicates), were tagged and measured for total length on 23 May. Individual tagged shoots were selected based on uniform length, moderate vigor, presence of two flower clusters, and uniform canopy position. Plots were designated to analyze $\mathrm{BN}$ variance as a function of plot, vine, and individual shoot. Shoot length measures were repeated on 30 May and 10 June. Full bloom occurred about 2 June. SGR was expressed as the length increase $(\mathrm{cm})$ per day between 23 May (about 10 nodes per shoot) and 10 June (about 20 nodes per shoot). The 23 May to 10 June period was chosen for SGR measurement because it is a period of rapid shoot growth, and research elsewhere suggested that the number of necrotic buds was determined within the 3-week period postbloom (Lavee et al., 1981).

Canopy density in the Prince Michel SGR experiment was quantified by point quadrat analysis (PQA) and PPF measurements within and outside canopy interiors. PQAs described in this report were performed as suggested by Smart et al. (1990); these involved probes every $10 \mathrm{~cm}$ (about 45 probes per replicate at Prince Michel) with the probe inserted horizontally and completely through the fruit zones. Probe contacts with leaves, fruit, and canopy gaps were recorded and used to generate percentage canopy gaps, leaf layer numbers, and the relative proportion of exterior to interior leaves. The PQA was done on 25 July. PPF values were obtained with a $1.0-\mathrm{m}$ line quantum sensor (model LI191SB) between 1100 and 1330 HR on 2 Aug. PPF measures were made on each vine, with the line sensor held parallel to the row within the fruit zone. Three such measures were made: one with the sensor face oriented skyward $\left(0^{\circ}\right)$; one facing $45^{\circ}$ to the north, and one facing $45^{\circ}$ to the south of the east-west oriented rows. In addition, a single exterior PPF reading was made for each vine by holding the sensor above the vine canopy with the sensor facing skyward. Ambient PPF values ranged from 1850 to 1900 $\mu \mathrm{mol} \cdot \mathrm{m}^{-2} \cdot \mathrm{s}^{-1}$ during the period of canopy measure. The three interior readings were averaged and divided by the ambient reading to obtain an average percentage of ambient PPF within fruit zones. Vines were managed for the balance of the growing season in a manner typical of the region. This included periodic mowing of row middles, up to two shoot hedgings, and effective pest management. Crop was uniformly light among plots. Although yield data were not collected from individual vines, grower records indicated that the Prince Michel 'Riesling' averaged about 6.5 t.ha ${ }^{-1}$ in 1991 and 1992. Tagged shoots were removed from vines in October 1991, and buds at nodes 1-20 were sectioned and assessed for BN. In addition, each shoot was measured for the widest diameter of the internode between nodes two and three, the number of nodes bearing brown, apparently mature periderm, and total length. Percent of nodes with mature periderm, BN, and average internode length were generated from measured data. Average BN among the first 20 nodes of each cane was regressed on that cane's SGR using SAS's general linear model procedures. SAS's nested procedure was used to estimate components of BN variance between plots, between vines of each plot, and between individual shoots of each vine, as suggested by Littel et al. (1991). Plots and vines were treated as random, independent variables, with shoots specified as the error component.

The relationship between early-season SGR and cumulative $\mathrm{BN}$ incidence was similarly evaluated at Somerset Vineyard during 1991 as part of another experiment described below.

Paclobutrazol growth retardant. The growth retardant paclobutrazol (PBZ) was applied to 'Riesling' vines at Prince Michel and Somerset Vineyards during 1992 to determine if $\mathrm{BN}$ incidence was reduced by reductions in SGR. In each vineyard, PBZ was applied three times $(10,18$, and $25 \mathrm{June})$ at $600 \mathrm{mg} \cdot \mathrm{liter}^{-1}$, followed by three applications $\left(9,16\right.$, and 23 July) at $300 \mathrm{mg} \cdot \mathrm{liter}^{-1}$. The 600 $\mathrm{mg} \cdot \operatorname{liter}^{-1}$ rate was equivalent to $1.4 \mathrm{~g} /$ vine a.i. at Prince Michel Vineyard and $2.1 \mathrm{~g} /$ vine a.i. at Somerset Vineyard (row and vine spacing for these vineyards reported elsewhere in Materials and Methods). Treatments were made to two- (Somerset vineyard) or three-vine (Prince Michel) plots, each replicated six times. A comparable number of check plots was used, and treatment and check plots were completely randomized. Before applying PBZ, four or six shoots, depending on vineyard, were selected for uniform vigor and were tagged and measured for total length. 
Initial-shoot length measurements were made 10 June and were repeated on 25 June and 2 July. Flower clusters were removed from tagged shoots in both vineyards. Initial PBZ applications coincided with $25 \%$ bloom at Prince Michel and $100 \%$ bloom at Somerset vineyard. PBZ was applied with a hand-sprayer, completely wetting foliage on both sides of the canopy, and using about 7 liters of water and $5 \mathrm{ml}$ of Tween-20 surfactant per treatment plot. PPF values were measured for each vine on 29 (Prince Michel) and 31 July (Somerset). In addition, PQAs were performed on 3 and 10 Aug. at Somerset and Prince Michel, respectively. PPF measures and PQAs. were performed essentially as described above for the 1991 SGR study. Vines were maintained by commercially acceptable practices, which included routine pest management sprays and two shoot hedgings. Shoot hedging was done by hand to maintain at least 20 nodes per shoot. Hedging was generally not necessary on PBZ-treated vines. The tagged shoots were removed in late-September, and buds at nodes 1-20 were sectioned and examined for BN. BN incidence was related to PBZ treatment and growth rate in the 2-week period following bloom.

Shoot density and artificial shade. Experiments were conducted at Somerset Vineyard during the 1991 and 1992 growing seasons to determine the effects of natural and artificial canopy shade on 'Riesling' BN incidence. Vines at Somerset were trained to a Casarsa training system, which consisted of twin vines (one on either side of a line post) spaced $3.6 \mathrm{~m}$ apart in rows $3.6 \mathrm{~m}$ wide. Vines were trained to opposing, 1.8-m long unilateral cordons 1.5 $\mathrm{m}$ above ground, which were modified from the original Casarsa system by spur-pruning. Shoots were positioned vertically upright with the aid of foliage catch wires. BN had been assessed in this vineyard in January 1991 and was found to average < 20\% among the first 20 nodes of canes. Three treatments were compared in 1991: 1) vines were shoot-thinned to 10 shoots per meter of row; 2) shoot thinning, as in treatment 1 , plus application of shade cloth above the vine canopy; and 3) vines adjusted to 20 shoots per meter of row. Ten single-vine replicates were used for each of the treatments in a completely randomized design. Shoot thinning was done immediately before bloom (23 May). The neutral black shadecloth used in treatment 2 reduced PPF by $64 \%$ and was installed and retained over the plant canopy from 15 July to 6 Aug. Véraison was perceived as a slight berry softening during the first week of August. The shadecloth formed a tent above the vine canopy so that foliage was entirely shaded while allowing a 30- to $60-\mathrm{cm}$ gap between the shade cloth and foliage. The shadecloth reduced radiant heating of vine canopies and reduced air temperature $<1 \mathrm{C}$. Five shoots were selected per vine at bloom (23 May) and tagged, and their total length was measured. Repeat length measurements were made 2 and 10 June to calculate SGR. Canopy density was rated by PQA and PPF measurements (1100 to 1315 $\mathrm{HR}$ ) on 30 July using procedures similar to those described above. Crop levels were similar among treatments. Grower records indicated that Somerset 'Riesling' averaged about $4.5 \mathrm{t} \cdot \mathrm{ha}^{-1}$ in 1991 and 1992. Cane diameter and length were recorded, and buds at nodes 1-20 were examined for BN on the tagged shoots in October 1991.

Shoot thinning and artificial shade treatments were repeated and expanded at Somerset Vineyard in 1992. Treatments were similar to those of 1991, with the addition of a 20 -shoot per meter treatment coupled with canopy shading, and additional plots to evaluate bud shading. Shadecloth used in artificial shading in 1992 produced a $92 \%$ reduction in PPF. Canopy artificial shade was erected on 13 July and removed 3 Aug.- - again, shortly before the onset of rapid fruit ripening (véraison). In separate treatments, buds were shaded by wrapping shoot stems with double-layered black muslin in such a way that buds, but not leaf blades or petioles, were shaded from 13 July to 3 Aug. The doubled muslin cloth reduced PPF levels to $<1 \%$ of ambient. All treatments consisted of two-vine plots, replicated eight times in a completely randomized design. Shoot thinning to either 10 or 20 shoots per meter of canopy was done 25 May, about 2 weeks before full bloom. As in the previously described experiment, canopy density among all treatment replicates was evaluated by measuring PPF in the fruit zone (1030 to $1200 \mathrm{HR}$ ) on 31 July and by PQA on 3 Aug. Bud necrosis was assessed on six canes per vine (12 per treatment replicate) on 22 Oct. 1992.

\section{Results}

Vineyard surveys. Bud necrosis refers to a condition of the primary bud, irrespective of the status of secondary buds, unless otherwise noted. BN was observed as early as July during 1990 surveys, but was assessed with more certainty in November of that year. In July, the interior of apparently healthy buds appeared light green when sectioned either longitudinally or cross-sectionally. Buds classified as necrotic were visibly discolored, with discoloration ranging from light tan to dark brown. Buds whose viability was uncertain were recorded as questionable. In contrast to the July survey, there was a more obvious distinction between viable and necrotic buds in November; in addition to pronounced browning, necrotic buds examined in the fall were frequently dry, and crumbled upon sectioning. The sum of questionable and clearly necrotic buds recorded in July roughly approximated the proportion of necrotic buds subsequently observed in November. Considering the uncertain status of many of the buds examined in July, only the November 1990 data are described, and BN was not

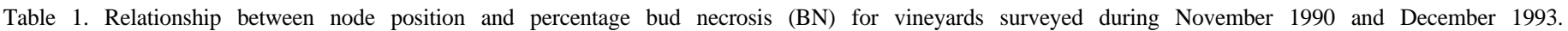

\begin{tabular}{|c|c|c|c|c|c|c|c|c|c|}
\hline \multirow[b]{3}{*}{ Nodes $^{y}$} & \multicolumn{9}{|c|}{ Vineyard } \\
\hline & \multicolumn{2}{|c|}{ Naked Mt. } & \multirow{2}{*}{$\begin{array}{c}\text { Flint Hill } \\
1990\end{array}$} & \multicolumn{2}{|c|}{ Meredyth } & \multirow{2}{*}{$\begin{array}{c}\text { Rapidan }^{2} \\
1990\end{array}$} & \multicolumn{2}{|c|}{ Prince Michel } & \multirow{2}{*}{$\begin{array}{c}\text { Somerset } \\
1990\end{array}$} \\
\hline & 1990 & 1993 & & 1990 & 1993 & & 1990 & 1993 & \\
\hline $1-4$ & $20.4 \mathrm{~B}^{\mathrm{x}}$ & $20.0 \mathrm{~B}$ & $39.2 \mathrm{~B}$ & $17.4 \mathrm{D}$ & $3.3 \mathrm{C}$ & $26.6 \mathrm{D}$ & $55.5 \mathrm{C}$ & $31.3 \mathrm{~B}$ & $5.4 \mathrm{~A}$ \\
\hline $5-8$ & $54.6 \mathrm{~A}$ & $40.8 \mathrm{~A}$ & $64.3 \mathrm{~A}$ & $42.2 \mathrm{C}$ & $9.2 \mathrm{BC}$ & $44.5 \mathrm{C}$ & $67.4 \mathrm{~B}$ & $34.0 \mathrm{~B}$ & $7.1 \mathrm{~A}$ \\
\hline $9-12$ & $49.0 \mathrm{~A}$ & $44.1 \mathrm{~A}^{\star}$ & $75.0 \mathrm{~A}$ & $56.0 \mathrm{BC}$ & $16.7 \mathrm{AB}$ & $54.4 \mathrm{BC}$ & $80.6 \mathrm{~A}$ & $65.6 \mathrm{~A}$ & $8.7 \mathrm{~A}$ \\
\hline $13-16$ & $50.0 \mathrm{~A}$ & $35.8 \mathrm{~A}$ & $84.7 \mathrm{~A}$ & $76.0 \mathrm{~A}$ & $21.6 \mathrm{~A}$ & $66.7 \mathrm{~A}$ & $89.4 \mathrm{~A}$ & $71.7 \mathrm{~A}$ & $16.0 \mathrm{~A}$ \\
\hline $17-20$ & $50.0 \mathrm{~A}$ & $13.0 \mathrm{~B}$ & $75.0 \mathrm{~A}$ & $62.5 \mathrm{AB}$ & $9.2 \mathrm{BC}$ & $66.7 \mathrm{~A}$ & --- & --- & $15.5 \mathrm{~A}$ \\
\hline
\end{tabular}

${ }^{2}$ Rapidan data are pooled across 'Riesling' grafted to three different rootstocks.

${ }^{y} \mathrm{BN}$ percentage data were classified and analyzed by node position on the shoot.

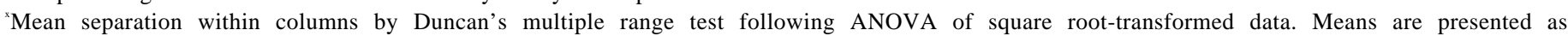
untransformed values, and those followed by the same letter are not significantly different at $P \leq 0.05$. 
Table 2. Comparison of average percentage bud necrosis $( \pm \mathrm{SD})$ for nodes 1-12 in 'Riesling' and 'Chardonnay' canes sampled from four vineyards during November 1990.

\begin{tabular}{|c|c|c|c|c|}
\hline Cultivar & Naked Mt. & Flint Hill & Meredyth & Prince Michel \\
\hline Riesling & $41.0 \pm 27.6$ & $59.3 \pm 24.5$ & $38.8 \pm 21.9$ & $66.5 \pm 19.8$ \\
\hline Chardonnay & $14.2 \pm 18.0$ & $1.9 \pm 3.7$ & $4.6 \pm 7.3$ & $6.8 \pm 7.6$ \\
\hline
\end{tabular}

Table 3. Mean shoot diameter, internode length, average percentage photosynthetic photon flux (PPF) for nodes 5 and 10 , and percentage bud necrosis (BN) among the first 20 buds of 'Riesling' shoots, as a function of apparent shoot exposure.

\begin{tabular}{lcccrr}
\hline \hline Vineyard & $\begin{array}{c}\text { Shoot } \\
\text { exposure }\end{array}$ & $\begin{array}{c}\text { Mean shoot } \\
\text { diam }(\mathrm{mm})\end{array}$ & $\begin{array}{c}\text { Mean internode } \\
\text { length }(\mathrm{cm})\end{array}$ & $\begin{array}{c}\text { PPF }^{2} \\
(\%)\end{array}$ & $\begin{array}{r}\text { BN } \\
(\%)\end{array}$ \\
\hline Meredyth & Exposed & $9.0 \mathrm{~A}^{y}$ & $4.9 \mathrm{~B}$ & $57.3 \mathrm{~A}$ & $1.9 \mathrm{~B}$ \\
& Shaded & $8.1 \mathrm{~A}$ & $6.8 \mathrm{~A}$ & $5.8 \mathrm{~B}$ & $22.2 \mathrm{~A}$ \\
Somerset & Exposed & $8.1 \mathrm{~A}$ & $4.8 \mathrm{~B}$ & $14.4 \mathrm{~A}$ & $19.9 \mathrm{C}$ \\
& Partially exposed & $9.5 \mathrm{~A}$ & $6.3 \mathrm{~A}$ & $4.8 \mathrm{~B}$ & $40.5 \mathrm{~B}$ \\
& Shaded & $8.9 \mathrm{~A}$ & $6.4 \mathrm{~A}$ & $2.0 \mathrm{~B}$ & $63.0 \mathrm{~A}$ \\
Naked Mt. & Exposed & $8.8 \mathrm{~A}$ & $7.6 \mathrm{~A}$ & $22.4 \mathrm{~A}$ & $16.4 \mathrm{~A}$ \\
& Shaded & $8.5 \mathrm{~A}$ & $7.2 \mathrm{~A}$ & $5.3 \mathrm{~B}$ & $24.0 \mathrm{~A}$
\end{tabular}

${ }^{\bar{P}} \mathrm{PPF}$ expressed as a percentage of total available PPF above the vine canopy.

'Mean separation within vineyards and columns by Duncan's multiple range test following ANOVA of square root-transformed data. Means are presented as untransformed values and those followed by the same letter are not significantly different at $P \leq 0.05$.

assessed before late-September in subsequent surveys and experiments.

Aside from the destruction of developing buds, the vines and vineyards examined in this work appeared healthy. Bloom-time leaf petiole analysis failed to reveal consistent imbalances in essential nutrients (data not shown), and there was no consistent association of insect, disease, or other pests that could explain the localized necrosis.

BN incidence among vineyards surveyed in November 1990 ranged from an average of $11 \%$ at Somerset to $73 \%$ at Prince Michel when all buds of the shoot were considered (Table 1). A reexamination of three of those vineyards in Fall 1993 revealed a somewhat lower percentage of BN, with Prince Michel Vineyard still showing the greatest incidence. The lowest frequency of necrotic buds was generally observed among the basal four nodes in all vineyards. Among other nodes, the incidence tended to increase with node distance from the shoot base, but parabolic patterns were evident at Naked Mountain and Meredyth in 1993. The common use of shoot hedging in most of these vineyards prevented a thorough examination of primary nodes beyond about position 20. In limited situations where this was possible, nodes that appeared after véraison tended to have a lower frequency of bud necrosis than buds that emerged before véraison (data not shown). There did not appear to be a meaningful relationship between the presence of a strong, persistent summer lateral and BN at a particular node; however, large shoots and canes typically had more summer laterals and more $\mathrm{BN}$ (data not shown).

The 1990 surveys also suggested that large shoots-those with relatively long internodes, basal internodes $\geq 10 \mathrm{~mm}$ in diameter, and bearing three or more persistent laterals among the first 20 nodes had a greater incidence of BN than smaller shoots (data not shown).

Where comparisons were made, 'Chardonnay' vines consistently expressed less BN than 'Riesling' vines grown in adjacent rows or blocks of the same vineyard (Table 2).

Shoot exposure. BN averaged 2\% on exposed shoots and 22\% on shaded shoots at Meredyth Vineyard in 1991 (Table 3). The average PPF levels at nodes 5 and 10 of exposed and shaded shoots at Meredyth were $57 \%$ and $6 \%$, respectively. Internodes of shaded shoots were typically longer than those of exposed shoots, although cane diameters were similar. A similar relationship between shoot exposure and $\mathrm{BN}$ incidence was found at Somerset Vineyard (Table 3). The exception to this pattern occurred with Naked Mountain data, where BN levels and average internode lengths for shaded and exposed shoots did not differ.

SGR. Postbloom SGR and cumulative BN incidence showed a significant, positive relationship for 'Riesling' vines at Prince Michel in 1991 (Fig. 1). BN incidence increased about 16\% for each $1 \mathrm{~cm}$ per day increase in SGR; however, SGR explained only about $40 \%$ of the variance in BN incidence. Regression of BN on either cane diameter or average internode length also revealed significant, positive relationships between those variables and BN (data not shown). There was no apparent relationship between the extent of cane maturation (ripe nodes) and BN (data not shown). Vines in the 10 replicate plots used in the Prince Michei growth rate study developed similar canopy densities: PQAs revealed an average $( \pm$ SD ) of $2.2 \pm 0.7$ leaf layers, $29 \% \pm 14 \%$ interior leaves, and $8 \% \pm 10 \%$ canopy gaps among the 10 plots. Percentage of ambient PPF measured in fruit zones averaged $4.5 \% \pm 4.1 \%$ for a day (2 Aug.) on which ambient levels ranged from 1850 to 1900 $\mu \mathrm{mol} \cdot \mathrm{m}^{-2} \cdot \mathrm{s}^{-1}$. An analysis of variance components using SAS's nested procedure indicated that the variance in $\mathrm{BN}$ associated with individual canes (error) was much greater than variance among vines or variance among plots (Table 4).

Simple regression of cane $\mathrm{BN}$ on cane diameter or on average internode length indicated that those variables had significant associations with $\mathrm{BN}$; however, neither variable explained more variability in BN than SGR at Prince Michel (data not shown). SGR was insignificant $(P \leq 0.07)$ in describing cane $\mathrm{BN}$ at Somerset Vineyard (data pooled among three treatments), although cane diameter and average internode length were significantly related to BN $(P \leq 0.01)$ (data not shown). Neither independent variable, however, explained $>5 \%$ of the variability in BN.

Paclobutrazol growth retardant. Paclobutrazol application significantly reduced SGR at the Prince Michel and Somerset vineyards (Table 5). Except for buds at nodes one through five of vines at Somerset, PBZ was also associated with large, significant reductions in $\mathrm{BN}$ incidence. Canopy characteristics were similar 


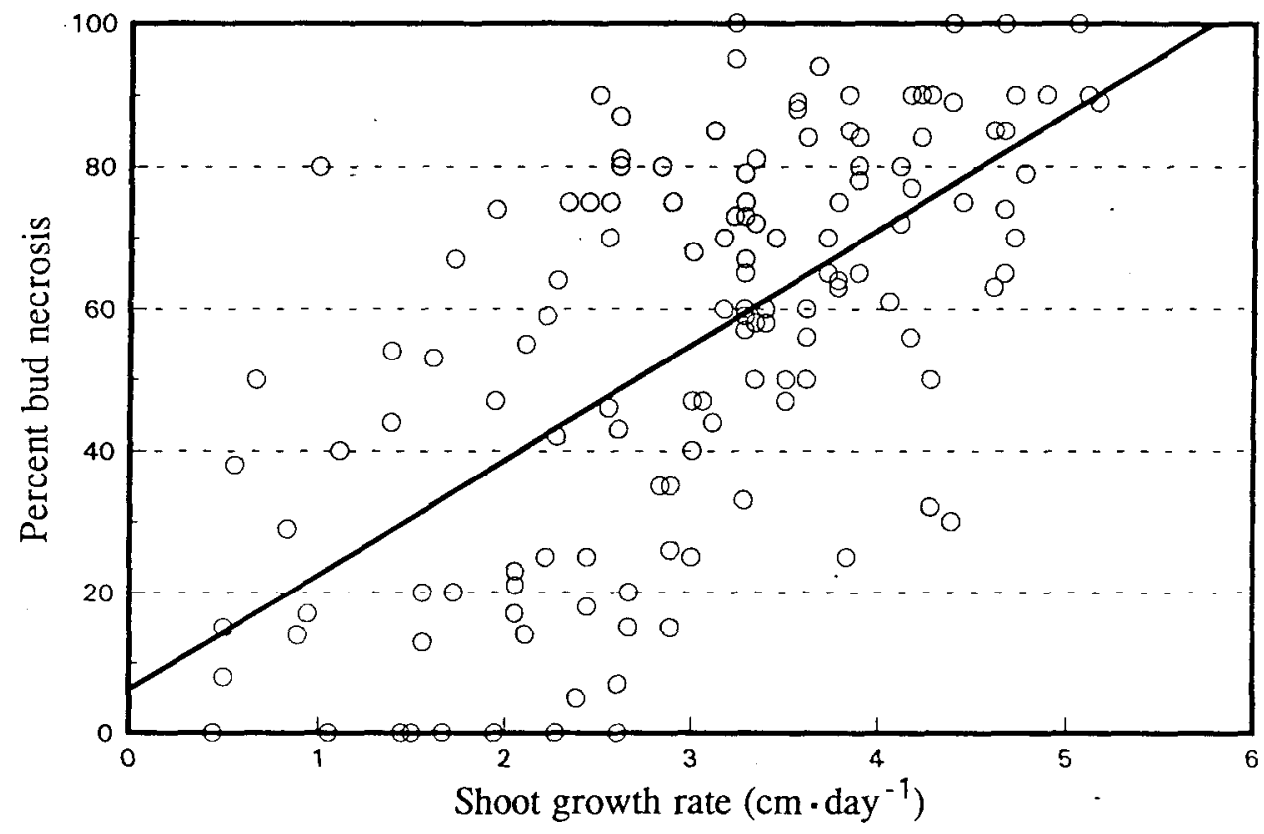

Fig. 1. Relationship between shoot growth rate (23 May to 10 June 1991) and BN incidence in early fall of the same shoots for 'Riesling' at Prince Michel vineyards. Each datum is the average bud necrosis incidence $(\%)$ among the first 20 nodes from the base of three canes collected from each of 50 vines. Linear regression slope $\left(\mathrm{y}=6.21+16.25 \mathrm{x} ; r^{2}=0.40\right)$ was significant at $P \leq 0.001$.

between PBZ-treated and check vines at Somerset, whereas PBZtreated vines at Prince Michel had greater PPF levels, a slightly lower leaf layer number, and 7\% fewer interior leaves.

Shoot density and artificial shade. Plots thinned to 10 shoots per meter of canopy had the same level of $\mathrm{BN}$ as those thinned to 20 shoots per meter in 1991 (Table 6). As expected, there were significant differences in canopy characteristics between these two treatments, with the greater shoot density associated with lower PPF levels and a greater proportion of interior leaves. Shoots of vines thinned to 10 shoots per meter of canopy averaged $3.3 \mathrm{~cm}$ of growth per day, whereas those thinned to 20 shoots per meter averaged only $2.4 \mathrm{~cm}$ per day. The 3-week application of $64 \%$

Table 4. Relative contribution of variance sources in 'Riesling' shoot growth rate study at Prince Michel, 1991.

\begin{tabular}{lrcrr}
\hline \hline Variance source & df & Mean squares & Variance component & Percentage of total \\
\hline Total & 137 & 813.0 & 825.8 & 100.0 \\
Block & 9 & 2549.2 & 116.6 & 14.1 \\
Vine & 38 & 936.3 & 121.8 & 14.8 \\
Shoot (error) & 90 & 587.4 & 587.4 & 71.1 \\
\hline
\end{tabular}

Table 5. Effect of paclobutrazol on canopy characteristics, shoot growth rate, and incidence of bud necrosis (BN) of 'Riesling' grapevines at Prince Michel and Somerset vineyards during 1992.

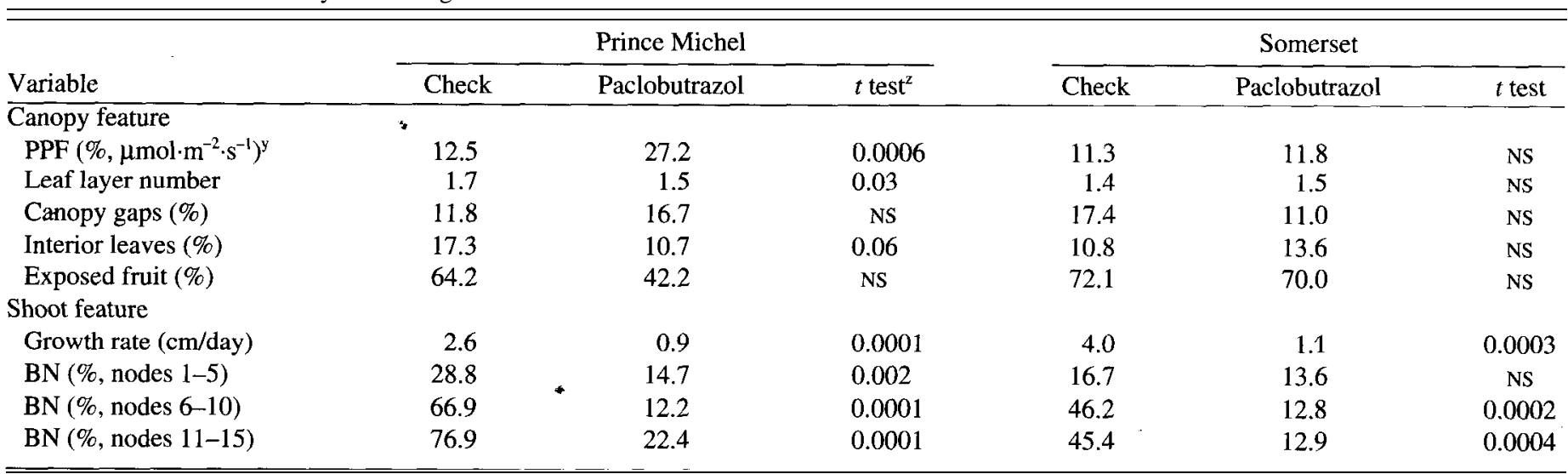

${ }^{2}$ Level of significance $(P)$ oft test of treatment means.

'Prince Michel readings taken 29 July; $1100-1230 \mathrm{HR}$; clear and sunny; ambient PPF levels of $1650-1850 \mu m_{0} \cdot \mathrm{m}^{-2} \cdot \mathrm{s}^{-1}$. Somerset readings taken 31 July; 1030-1200 HR; clear and sunny; ambient PPF levels of $1600-1800 \mathrm{pmol} \cdot \mathrm{m}^{-2} \cdot \mathrm{s}^{-1}$.

${ }^{\times} \mathrm{PPF}=$ photosynthetic photon flux.

${ }^{\mathrm{NS}}$ Nonsignificant. 


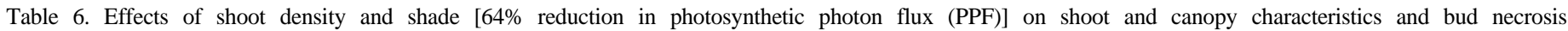
(BN) incidence of 'Riesling' vines at Somerset Vineyard during 1991. Percentage data were arcsin-transformed before analysis.

\begin{tabular}{|c|c|c|c|c|c|c|c|c|c|}
\hline \multirow[b]{2}{*}{$\begin{array}{l}\text { Shoots/ } \\
\text { m }\end{array}$} & \multirow[b]{2}{*}{ Shade } & \multirow[b]{2}{*}{$\begin{array}{l}\mathrm{SGR}^{2} \\
(\mathrm{~cm} / \mathrm{day})\end{array}$} & \multirow[b]{2}{*}{$\begin{array}{c}\text { Mean internode } \\
\text { length }(\mathrm{cm})\end{array}$} & \multirow[b]{2}{*}{$\begin{array}{c}\text { Ripe } \\
\text { nodes }(\%)^{y}\end{array}$} & \multicolumn{3}{|c|}{ Point quadrat analysis } & \multirow[b]{2}{*}{$\mathrm{PPF}^{\mathrm{x}}$} & \multirow[b]{2}{*}{$\begin{array}{c}\text { Mean } \\
\text { BN (\%) }\end{array}$} \\
\hline & & & & & $\begin{array}{c}\text { Leaf } \\
\text { layers }\end{array}$ & $\begin{array}{l}\text { Canopy } \\
\text { gaps (\%) }\end{array}$ & $\begin{array}{c}\text { Interior } \\
\text { leaves }(\%)\end{array}$ & & \\
\hline$\overline{10}$ & No & $3 . \overline{3}$ & 5.5 & 95.9 & 1.3 & 20.0 & 8.3 & $11 . \overline{6}$ & 37.6 \\
\hline 20 & No & 2.4 & 4.9 & 87.3 & 3.3 & 1.3 & 43.2 & 1.9 & 37.8 \\
\hline 10 & Yes & 3.0 & 5.3 & 96.8 & 1.7 & 11.5 & 13.3 & 4.7 & 38.4 \\
\hline \multicolumn{10}{|l|}{ Contrast } \\
\hline 10 vs. 20 shoots $/ \mathrm{m}$ & & $* *$ & NS & $* *$ & $* * *$ & $* * *$ & $* * *$ & $* * *$ & NS \\
\hline Shade vs. no shade & & $* * *$ & $* *$ & NS & $* * *$ & $* * *$ & $* * *$ & $*$ & NS \\
\hline
\end{tabular}

${ }^{2} \mathrm{SGR}=$ shoot growth rate.

${ }^{y}$ Ripe nodes were those that bore brown periderm when $\mathrm{BN}$ was rated in October 1991.

${ }^{\mathrm{x}}$ Photosynthetic photon flux $\left(\mu \mathrm{mol} \cdot \mathrm{m}^{-2} \cdot \mathrm{s}^{-1}\right)$, reported as a percentage of ambient value measured in canopy fruit zone. Ambient PPF levels ranged from 1000 to $1750 \mu \mathrm{mol} \cdot \mathrm{m}^{-2} \cdot \mathrm{s}^{-1}$ on day of measure.

${ }^{\mathrm{Ns}}, * * * * * *$ Nonsignificant or significant at $P \leq 0.05,0.01$, or 0.001 , respectively.

shade, coupled with thinning to 10 shoots per meter, was associated with the same level of $\mathrm{BN}$ as observed with nonshaded vines.

At each node position examined in the 1992 experiment, BN incidence was significantly greater with canopies thinned to 20 shoots per meter than where canopies had been thinned to 10 shoots per meter (Table 7). Average BN incidence and incidence among nodes one to five was lower among canopy shade plots than where shade had not been applied. Bud shading appeared to cause somewhat greater BN levels than canopy shading, but those differences were not significant when compared with pooled shoot density data. Canopies thinned to 10 shoots per meter averaged 1.5 leaflayers, roughly one-half the thickness of canopies thinned only to 20 shoots per meter. The greater shoot density afforded by 20 shoots per meter also resulted in fewer canopy gaps, a greater proportion of interior leaves, and reduced PPF levels in fruit zones compared to canopies thinned to 10 shoots per meter.

\section{Discussion}

BN observed with 'Riesling' grapes in Virginia appeared, in many respects, similar to comparable disorders described with other cultivars in Israel (Lavee et al., 1981), Chile (Perez and Kliewer, 1990), California (Morrison and Iodi, 1990), and Japan
(Naito et al., 1989). 'Chardonnay' was relatively unaffected, but data from a cultivar evaluation study at the Winchester Agricultural Research and Extension Center showed that BN was variably expressed in other winegrape cultivars (Wolf and Cook, 1994). Initial indications of $\mathrm{BN}$ could be observed as early as 6 weeks after bloom as a browning of the primary bud. Unpublished histologic examinations suggest that necrosis begins at or before bloom of the current year's clusters in Virginia. The level of necrosis varies from year to year, but vineyards that express severe levels appear to do so annually.

The pattern of necrotic buds along the shoot has generally been reported as most frequent among the basal buds, with decreasing frequency as buds are examined acropetally (Lavee et al., 1981; Morrison and Iodi, 1990; Perez and Kliewer, 1990). In our studies, the lowest frequency of necrosis was observed with the first few basal buds and the more distal buds of unhedged shoots. It is unlikely that this pattern reflects node exposure because we observed the pattern with high-trained, shoot-positioned vines at Meredyth, and with vines shoot-thinned to 10 shoots per meter of canopy; a density promoting uniformly good exposure of all nodes for the entire season. The pattern of BN incidence observed here parallels patterns of vegetative (leaf primordia) and reproductive (inflorescence) differentiation (Buttrose, 1969; 1970), but a direct

Table 7. Effects of shade [92\% reduction in photosynthetic photon flux (PPF)] and shoot density on canopy characteristics and bud necrosis (BN) incidence (by node position) of 'Riesling' in 1992. Shade consisted of whole canopy or buds only. Percentage data were arcsin-transformed before a $n$ a 1 y s i s

\begin{tabular}{|c|c|c|c|c|c|c|c|c|c|}
\hline \multirow{3}{*}{$\begin{array}{l}\text { Shoots/ } \\
\mathrm{m}\end{array}$} & \multirow[b]{3}{*}{ Shade } & \multicolumn{3}{|c|}{ Point quadrat analysis } & \multirow[b]{3}{*}{$\mathrm{PPF}^{\mathrm{z}}$} & & & & \\
\hline & & \multirow{2}{*}{$\begin{array}{l}\text { Leaf } \\
\text { layers }\end{array}$} & \multirow{2}{*}{$\begin{array}{l}\text { Canopy } \\
\text { gaps (\%) }\end{array}$} & \multirow{2}{*}{$\begin{array}{c}\text { Interior } \\
\text { leaves }(\%)\end{array}$} & & \multicolumn{4}{|c|}{$\mathrm{BN}(\%)$} \\
\hline & & & & & & $1-5$ & $6-10$ & $11-15$ & Mean \\
\hline 10 & None & 1.4 & 17.7 & 14.3 & 10.8 & 19.5 & 33.1 & 35.6 & 30.8 \\
\hline 10 & Canopy & 1.6 & 8.9 & 16.0 & 0.9 & 19.1 & 26.0 & 27.7 & 24.5 \\
\hline 10 & Bud & 1.3 & 15.2 & 10.8 & $15.2^{y}$ & 30.6 & 33.9 & 37.0 & 33.5 \\
\hline 20 & None & 3.4 & 0.9 & 44.9 & 2.1 & 31.8 & 52.5 & 51.3 & 44.5 \\
\hline 20 & Canopy & 3.1 & 5.3 & 42.7 & 0.2 & 23.3 & 44.6 & 39.3 & 36.3 \\
\hline 20 & Bud & 2.9 & 13.7 & 36.0 & $1.8^{y}$ & 35.5 & 54.4 & 47.5 & 43.7 \\
\hline \multicolumn{10}{|l|}{ Contrast } \\
\hline \multicolumn{2}{|c|}{10 vs. 20 shoots/m of canopy } & $* * *$ & $* *$ & $* * *$ & $* * *$ & $*$ & $* * *$ & $* *$ & $* * *$ \\
\hline \multicolumn{2}{|c|}{ Canopy shade vs. no shade } & NS & NS & N S & $*$ & $* *$ & NS & NS & $*$ \\
\hline \multicolumn{2}{|c|}{ Bud vs. canopy shading } & NS & NS & NS & $* * *$ & NS & NS & NS & NS \\
\hline
\end{tabular}

${ }^{2}$ Photosynthetic photon flux density $\left(\mu \mathrm{mol} \cdot \mathrm{m}^{-2} \cdot \mathrm{s}^{-1}\right)$, reported as a percentage of ambient value measured in canopy fruit zone. Ambient PPFD levels ranged from 1650 to 1850 on day of measure.

${ }^{y} \mathrm{PPF}$ measured in canopy fruit zone; buds were shaded with black muslin to < $1 \%$ of ambient PPF.

Ns, $* * * * * *$ Nonsignificant or significant at $P \leq 0.05,0.01$, or 0.001 , respectively. 
relationship between bud differentiation and $\mathrm{BN}$ has conflicting support. Lavee et al. (1981) reported a reduced tendency toward necrosis with increased inflorescence differentiation. Morrison and Iodi (1990) observed no difference in BN frequency among 'Flame Seedless' buds that had differentiated clusters compared to buds that had differentiated only tendrils. Cultivar may affect the pattern of necrosis. In Japan, V. Zubrusca Bailey 'Campbell Early' exhibited a pattern of decreasing $\mathrm{BN}$ with increasing node number, while 'Pione' and 'Kyoho' exhibited a parabolic pattern (Naito et al., 1985; 1989) similar to that observed here with 'Riesling'. BN incidence as a function of node position has implications for compensatory pruning and training. 'Thompson Seedless' is typically cane-pruned to compensate for low fruitfulness of basal buds (Winkler et al., 1974). Cane pruning would also be useful for cultivars that exhibit decreased BN frequency with increased node position. Our observation of reduced $\mathrm{BN}$ frequency among basal buds of 'Riesling' argues for spur-pruning to retain a higher proportion of live primary buds.

The relationship between shoot vigor and $\mathrm{BN}$ was typically positive and significant, whether vigor was judged or measured as cane diameter, average internode length, or SGR over specified periods. In addition, we found that SGR effects on $\mathrm{BN}$ could be isolated from canopy shade effects. For example, where canopy density was kept sparse for the entire season, such as the SGR study at Prince Michel and the paclobutrazol experiments, the more rapidly elongating shoots typically exhibited more necrotic buds at the end of the season. The positive relationship between SGR and increased BN may have several bases. Lavee et al. (198 1) proposed that elevated gibberellin levels associated with vigorous shoot growth led to BN. BN frequency was increased when gibberellic acid (GA) was applied up to 2 weeks after bloom to 'Queen of Vineyard' vines (Ziv et al., 1981). Buds were insensitive to GAinduced necrosis once they were well differentiated. Bioassays suggested that gibberellin-like activity was greater in buds from vigorous (high $\mathrm{BN}$ frequency) vines than in buds from normal (low BN frequency) vines. Similarly, Naito et al. (1986) reported that $100 \mathrm{mg} \cdot$ liter $^{-1}$ of GA applied either 9 days before, or 7 days after bloom, increased shoot vigor and $\mathrm{BN}$ among nodes five through nine of 'Kyoho' vines. Contrary to the Israeli and Japanese studies, Morrison and Iodi (1990) found no effect of GA on BN incidence when GA was applied at 9 and 17 days after bloom to a normally fruitful 'Thompson Seedless' vineyard. Morrison and Iodi suggested that inconsistent effects of GA may be due to cultivar differences in sensitivity to exogenous GA. Cultivar differences in phytotoxic responses to exogenous GA have been recognized for more than 30 years (Weaver, 1960).

The reduction in $\mathrm{BN}$ incidence with application of paclobutrazol appeared associated with reductions in shoot vigor, rather than alterations of canopy density or canopy light environment. A more fundamental role of paclobutrazol may relate to its inhibitory effects on gibberellin biosynthesis (Lever, 1986), if BN originates from elevated gibberellin levels as suggested by Lavee et al. (1981). Experiments with growth retardants that do not inhibit gibberellin biosynthesis would help distinguish growth rate effects from more basic effects. Succinic acid-2, 2-dimethylhydrazine (SADH) reduced mean internode length and $\mathrm{BN}$ incidence with 'Kyoho' (V. labrusca Bailey) vines in Japan (Naito et al., 1985, 1986). The actual reduction in $\mathrm{BN}$ varied with node position and with time of application. At node positions five to eight, BN was reduced from about $85 \%$ in control shoots to about $50 \%$ in vines treated with SADH 22 days before bloom. Similar reductions in $\mathrm{BN}$ incidence were observed at nodes 5 to 20 . Nodes one to four, which had elongated before SADH application, were unaffected.
SADH was less effective in reducing vigor and $\mathrm{BN}$ when applied 10 days postbloom (Naito et al., 1986).

Natural and artificial canopy shade produced inconsistent effects on 'Riesling' BN in this work. Buds that were collected from nodes or shoots that were likely shaded for much of their development were more apt to be necrotic than were buds collected from well-exposed shoots. That pattern was similar to Pérez-Harvey's (1991) report of a strong $\left(r^{2}=0.92\right)$, inverse correlation between BN of randomly sampled 'Thompson Seedless' buds and the exposure of those buds. In Pérez-Harvey's survey, BN decreased from $63 \%$ to $10 \%$ when the respective bud exposure increased from $<15$ to $>60 \mu \mathrm{mol} \cdot \mathrm{m}^{-2} \cdot \mathrm{s}^{-1}$. We noted exceptions in the relationship between shoot exposure and $\mathrm{BN}$ incidence, including the occasional high incidence of $\mathrm{BN}$ on moderately vigorous canes that were in isolated positions of the trellis; i.e., positions that were likely well exposed to sunlight for the entire growing season. Our experiments with artificial canopy and individual bud shading did not increase $\mathrm{BN}$ incidence, results that were dissimilar to those of Pérez and Kliewer (1990). Recent, unpublished work has also shown no increase in $\mathrm{BN}$ incidence when $92 \%$ shade was applied for a 3-week period shortly after bloom. The lack of shade effects and the difference in patterns of $\mathrm{BN}$ by node position suggest that $\mathrm{BN}$ of 'Riesling' observed in Virginia and BN of seedless table grapes may have different etiologies. Given the inconsistent effect of natural shade and the apparent lack of artificial shade effects, we draw the same conclusion as that reached by Morrison and Iodi (1990): shade may aggravate BN, but shade is not likely the basic cause of 'Riesling' BN.

In conclusion, BN was widespread among Virginia 'Riesling' vineyards. Variation among shoots on a vine was greater than or equal to variation between comparably-sized vines. Shoot vigor (growth rate, stem diameter, or internode length) and $\mathrm{BN}$ were often positively correlated, and grower practices that manage vigor are recommended where this disorder occurs. The lowest frequency of necrotic buds on a given shoot or cane was found among the basal four to five nodes, and some compensation was possible with spur-pruning. This pattern of $\mathrm{BN}$ on the shoot, as related to node position, is unique among similar reports of grape $\mathrm{BN}$. Although exceptions occurred, natural canopy shade appeared to increase BN, while 3-week periods of artificial shade had no effect. From a practical standpoint, canopy management measures that result in good canopy insolation, such as shoot thinning and shoot positioning, may be beneficial and may be warranted for reasons other than BN mitigation. Nevertheless, optimizing shoot exposure does not eliminate $\mathrm{BN}$ and a search for more fundamental causes is needed.

\section{Literature Cited}

Bindra, A.S. and J.S. Chohan. 1975. Flower-bud killing in Anab-E-Shahi grapes. Indian J. Mycol. Plant Pathol. 5:63-68.

Buttrose, MS. 1969. Fruitfulness in grapevines: Effects of changes in temperature and light regimes. Bot. Gaz. 130:173-179.

Buttrose, M.S. 1970. Fruitfulness in grapevines: development of leaf primordia in buds in relation to bud fruitfulness. Bot. Gaz. 131:78-83. Christensen, L.P. and J.D. Boggero. 1985. A study of mineral nutrition relationships of waterberry in Thompson Seedless. Amer. J. Enol. Viticult. 36:57-64.

Dry, P.R. and G.G. Coombe. 1994. Primary bud-axis necrosis. I. Natural incidence and correlation with vigour. Vitis 33:225-230.

Gill, P.A. 1985. Lateral bud necrosis in the black currant (Ribes nigrum L.). Plant Pathol. 34:297-299.

Hellali, R., J. Lin, and D.E. Kester. 1978. Morphology of noninfectious bud failure symptoms in vegetative buds of almond (Prunus amygdalus Batsch). J. Amer. Soc. Hort. Sci. 103:459-464 
Lavee, S. 1987. Necrosis in grapevine buds (Vitis vinifera $c v$. Queen of Vineyard) III. Endogenous gibberellin levels in leaves and buds. Vitis 260:225-230.

Lavee, S., H. Melamud, M. Ziv, and Z. Bernstein. 1981. Necrosis in grapevine buds (Vitis vinifera cv. Queen of-Vineyard) I. Relation to vegetative vigor. Vitis 20:8-14.

Lever, B. G. 1986. 'Cultar'-A technical overview. Acta Hort. 179:459466.

Littell, R.C., R.J. Freund, and PC. Spector. 1991. SAS system for linear models. 3rd ed. SAS Inst., Cary, N.C:

May, P., P.R. Clingeleffer, and C.J. Brien. 1976. Sultana (Vitis vinifera L.) canes and their exposure to light. Vitis 14:278-288.

Morrison, J. C. and M. Iodi. 1990. The development of primary bud necrosis in Thompson Seedless and Flame Seedless grapevines. Vitis 29: $133-144$

Naito, R., H. Yamamura, and M. Sugahara. 1985. Studies on the necrosis in grapevine buds (II) Effects of the time of prebloom SADH application by foliar spray on the occurrence of bud necrosis in 'Kyoho' vine. Bul. Fat. of Agr., Shimane Univ., Japan 19:7-10.

Naito, R., H. Yamamura, and K. Yoshino. 1986. Effects of shoot vigor and foliar application of GA and SADH on the occurrence of bud necrosis in 'Kyoho' grape. J. Jpn. Soc. Hort. Sci. 55:130-137.

Naito, R., H. Yamamura, and S. Munesue. 1987. Studies on the necrosis in grapevine buds (III) The time of the occurrence of bud necrosis in 'Kyoho' and the relation between its occurrence and the amounts of nutritional elements in buds. Bul. Fat. of Agr., Shimane Univ., Japan 21:10-17.

Naito, R., H. Ueda, and S. Munesue. 1989. Studies on the necrosis in grapevine buds (IV) Relation between the occurrence of bud necrosis and the shoot emerging from lateral buds on fruiting canes in 9 Japanese leading cultivars. Bul. Fat. of Agr., Shimane Univ., Japan 23:1-6.

Pastena, B. 1990. Sulle gemme cieche della vite. Vignevine 6:53-59.

Perez, J. and W.M. Kliewer. 1990. Effect of shading on bud necrosis and bud fruitfulness of Thompson Seedless grapevines. Amer. J. Enol. Viticult. 41:168-175.

Perez-Harvey, J. 1991. The influence of nitrogen fertilization on bud necrosis and bud fruitfulness of grapevines. Proc. Intl. Symp. Nitrogen in Grapes and Wine, Seattle, Wash., 18-19 June 1991. p. 110-115.

Pratt, C. 1974. Vegetative anatomy of cultivated grapes-A review. 1974. Amer. J. Enol. Viticult. 25:131-150.

Simons, B.R. and M.W. Smith. 1991. The influence of gibberellin biosynthesis-inhibiting growth regulators on bract necrosis in 'Gutbier V-14 Glory' poinsettia. Scientia Hort. 48:117-123.

Smart, R.E., J.K. Dick, I.M. Gravett, and B.M. Fisher. 1990. Canopy management to improve grape yield and wine quality-Principles and practices. S. Afr. J. Enol. Viticult. 11:3-17.

Weaver, R.J. 1960. Toxicity of gibberellin to seedless and seeded varieties of Vitis vinifera. Nature 187:1135-1136.

Winkler, A.J., J.A. Cook, W.M. Kliewer, and L.A. Lider. 1974. General viticulture. Univ. of California Press, Berkeley.

Wolf, T. K. and M. Kay Cook, 1994. Cold hardiness of dormant buds of grape cultivars: Comparison of thermal analysis and field survival. HortScience 29:1453-1455.

Ziv, M., H. Melamud, Z. Bernstein, and S. Lavee. 1981. Necrosis in grapevine buds (Vitis vinifera cv. Queen of vineyard) II. Effect of gibberellic acid $\left(\mathrm{GA}_{3}\right)$ application. Vitis 20:105-114. 